\title{
Measurement of Cesium Diffusion Coefficients in Graphite IG-110
}

\author{
L.M. Carter ${ }^{a}$, J.D. Brockman ${ }^{b}$, S.K. Loyalka ${ }^{c}$, J.D. Robertson ${ }^{a, b}$ \\ ${ }^{a}$ Department of Chemistry, University of Missouri, 125 Chemistry Building, Columbia, MO 65211, United States \\ ${ }^{b}$ University of Missouri Research Reactor Center, University of Missouri, 1513 Research Park Dr., Columbia, Mo 65211, United \\ States \\ ${ }^{c}$ Nuclear Science and Engineering Institute, University of Missouri, E2433 Lafferre Hall, Columbia, MO 65211, United States
}

*Corresponding author. Tel.: +1 5738848095

Email address: brockmanjd@missouri.edu

\begin{abstract} temperature range of $1100-1300 \mathrm{~K}$. We have obtained:

$D_{C s}=\left(1.0 \times 10^{-7} \mathrm{~m}^{2} / \mathrm{s}\right) \exp \left(\frac{-1.1 \times 10^{5} \mathrm{~J} / \mathrm{mol}}{R T}\right)$

and, compared our results with those available in the literature.
\end{abstract}

An understanding of the transport of fission products in High Temperature Gas-Cooled Reactors (HTGRs) is needed for operational safety as well as source term estimations. We have measured diffusion coefficients of Cs in IG-110 by using the release method, wherein we infused small graphite spheres with Cs and measured the release rates using ICP-MS. Diffusion behavior was investigated in the

\section{Introduction}

High Temperature Gas-Cooled Reactors (HTGRs) have five barriers to fission product (FP) release (the TRISO fuel coating, the fuel elements, core graphite, primary coolant system, and the reactor building). While very substantial understandings and data already exist [1-3], there is a need for new data and computational tools as new types of nuclear graphite are being used, or will be used than in the past. Our purpose in this paper is to describe a method we have developed to obtain diffusion coefficients of Cs in IG-110 graphite at HTGR temperatures. The method uses inductively coupled plasma-mass spectrometry (ICP-MS) to measure Cs release rates from graphite spheres infused with Cs. The method is general, and can be applied to measurements of diffusion coefficients of other substances or mixtures of substances as well.

We note that the release and profile methods were used previously for measurements of diffusion coefficients of Cs and other FP diffusants in graphite [4-11]. In these works graphite samples were impregnated with the FP material, and then annealed at specified temperatures and for certain time 
periods to effect release of FP. These techniques involved radioanalytical measurements of initial and final FP concentration in the graphite sample (release method), or the concentration profile by sectioning of the sample (profile method). The diffusion coefficients were then extracted from the data by comparison with theoretical results as given by the diffusion equation. Additionally, in one case [7] the release rates of $\mathrm{Cs}-134$ from a sphere were measured using gamma spectrometry, and the diffusion coefficient was extracted by comparing this rate to the theoretical expression for the release rate. Typical results for $\mathrm{H}-451$, matrix graphite A-3, HS-1-1, and IG-110 that have been reported are:

Table 1: Selected previous measurements of Cs diffusion in various graphites

\begin{tabular}{|c|c|c|c|c|c|}
\hline \multirow[t]{2}{*}{ Investigators } & \multirow[t]{2}{*}{ Graphite } & \multirow[t]{2}{*}{ Method } & \multicolumn{2}{|c|}{$D=D_{0} \exp (-E / R T)$} & \multirow[t]{2}{*}{$D\left(m^{2} s^{-1}\right)$} \\
\hline & & & $D_{0}\left(\mathrm{~m}^{2} \mathrm{~s}^{-1}\right)$ & $E\left(\mathrm{~J} \cdot \mathrm{mole}^{-1}\right)$ & \\
\hline Meyers [6] & $\begin{array}{l}\text { H-451, cylindrical } \\
\text { samples }\end{array}$ & $\begin{array}{l}\text { Used sectioning } \\
\text { technique. Diffusion } \\
\text { trapping included; data } \\
\text { obtained between } \approx 850 \text { to } \\
950^{\circ} \mathrm{C}\end{array}$ & & & $\begin{array}{l}2.20 \times 10^{-10} \\
\text { to } 1.31 \times 10^{-9}\end{array}$ \\
\hline Leyers [7] & $\begin{array}{l}\text { Matrix A3, } \\
\text { spherical samples }\end{array}$ & $\begin{array}{l}\text { Helium flow over } 1 \mathrm{~cm} \\
\text { sphere infused with Cs- } \\
134 \text {; gamma activity } \\
\text { measurement for release } \\
\text { rate }\end{array}$ & $2.01 \times 10^{-4}$ & $1.98 \times 10^{5}$ & \\
\hline Hoinkis [8] & Matrix A3-3 & $\begin{array}{l}\text { Doping with Cs-137 and } \\
\text { release }\end{array}$ & $1.99 \times 10^{-4}$ & $1.81 \times 10^{5}$ & \\
\hline Evans [9] & HS-1-1 & Sectioning technique & $4.44 \times 10^{-2}$ & $1.27 \times 10^{5}$ & \\
\hline \multirow[t]{2}{*}{$\begin{array}{l}\text { Hayashi and } \\
\text { Fukuda [10] }\end{array}$} & IG-110 graphite & $\begin{array}{l}\text { Sectioning of diffusion } \\
\text { couple acceptor specimen }\end{array}$ & $\begin{array}{l}1.2 \times 10^{-4} \\
(\text { Series A) }\end{array}$ & $1.12 \times 10^{5}$ & \\
\hline & & & $\begin{array}{l}1.7 \times 10^{-4} \\
\text { (Series B) }\end{array}$ & $9.5 \times 10^{4}$ & \\
\hline Hayashi [11] & $\begin{array}{l}\text { Irradiated IG-110 } \\
\text { graphite }\end{array}$ & $\begin{array}{l}\text { Sectioning of IG- } 110 \\
\text { specimen from OGL-1fuel } \\
\text { irradiation experiments }\end{array}$ & $9.0 \times 10^{-6}$ & $1.57 \times 10^{5}$ & \\
\hline
\end{tabular}

\section{Materials and Methods}

\subsection{The release model and method}

One considers a sample impregnated with a FP or any other volatile. As the sample is heated to a higher temperature, the FP is released from the sample at a time dependent rate. This release rate is dependent on many parameters as the sample may be porous, fractured, contain trapping 
contaminants, and the initial distribution of the FP itself may not be uniform or precisely known. The sample shape may deviate from an ideal geometry, and because of flow of helium or some other gas over the sample, surface mass transfer may not be easily estimated. While all these factors need to be eventually considered, ideally, one assumes that the release rate is dominated by the diffusion equation, and in this instance the effect of other factors is small. If a mathematical expression for the release rate, (dependent on the diffusion coefficient and known sample dimensions) and hence the cumulative release over a certain time period, are obtained, then by comparing the expressions for rate or cumulative release with the data, one can obtain the diffusion coefficient. The case of the spherical geometry is especially simple, where:

$\frac{\partial C(r, t)}{\partial t}=\frac{1}{r^{2}} \frac{\partial}{\partial r}\left(D r^{2} \frac{\partial C(r, t)}{\partial r}\right)$

With the initial and boundary conditions:

$C(r, 0)=C_{0}$

$C(0, t)=$ finite

$C(R, t)=0$

Here, $C(r, t)$ is the concentration of the FP $\left(\mathrm{g} / \mathrm{m}^{3}\right), D$ is the diffusion coefficient $\left(\mathrm{m}^{2} / \mathrm{s}\right), r$ is the radial coordinate $(\mathrm{m}), R$ is the radius of the sphere $(\mathrm{m})$, and $t$ is the time $(\mathrm{s}) . C_{0}$ is a constant; the initial uniform concentration.

This is a well- known equation of mass transfer, and can be solved by series expansion or transform techniques [12]. In particular, the cumulative fractional release (defined as the ratio of total mass release of FP from the sphere at time $t$ to the initial total mass of FP in the sphere), can be expressed as:

$F(t)=1-\frac{6}{\pi^{2}} \sum_{n=1}^{\infty} \frac{1}{n^{2}} e^{-\left(\frac{n \pi}{R}\right)^{2} D t}$

This series converges slowly, especially for short times. For extraction of the diffusion coefficient, a short time solution (obtained through the Laplace Transformation) is more convenient. This solution is known to be:

$F(t)=6 \sqrt{\frac{D t}{\pi R^{2}}}-3 \frac{D t}{R^{2}}$

This solution is considered to be valid for a fairly long range of time (up to and exceeding $90 \%$ release), and generally for short times (up to $30 \%$ release) one can use just the first term only [12]. The diffusion coefficient is calculated by fitting solutions of the fractional release equation above to fractional release data. We can also use the theoretical rate equation, which is the product of the derivative of the above and the initial FP mass, for comparisons with the corresponding measurements. The short time theoretical release rate $Z_{R}(t)(\mathrm{g} / \mathrm{s})$ is:

$Z_{R}(t)=3 m_{0}\left(\sqrt{\frac{D}{\pi R^{2} t}}-\frac{D}{R^{2}}\right)$

where $m_{0}$ is the total initial mass ( $\mathrm{g}$ ) of FP in the sphere. We have used both the cumulative release and the release rate data and expressions for calculation of diffusion coefficients and have observed agreement among the obtained values. 


\subsection{Materials and sample preparation}

The graphite used in this study was IG-110 manufactured by Toyo Tanso. It is produced using an isostatic rubber press process and is semi-isotropic. Spherical samples were milled to a radius of $0.2 \mathrm{~cm}$. The spheres were infused (impregnated) with cesium using a modified procedure that was adapted from Hayashi and Fukuda [10]. Ten graphite spheres were loaded into a quartz vial $(0.6 \mathrm{~cm}$ diameter, $4 \mathrm{~cm}$ length) with $600 \mu \mathrm{g}$ of $\mathrm{Cs}$ in the form of $\mathrm{CsNO}_{3}$. The vial was then sealed under vacuum with a measured pressure of $40 \mathrm{mTorr}$. The sealed quartz vial was heated to $500^{\circ} \mathrm{C}$ to convert the nitrate salt to elemental $\mathrm{Cs}$ by the following reaction:

$2 \mathrm{CsNO}_{3(s)} \rightarrow 2 \mathrm{Cs}_{(l)}+2 \mathrm{NO}_{2}(g)+\mathrm{O}_{2}(g)$

After 1 hour, the temperature was increased to $1100^{\circ} \mathrm{C}$ and maintained for 99 additional hours to uniformly distribute cesium within the graphite spheres. The temperature was reduced at a rate of $1^{\circ} \mathrm{C} / \mathrm{min}$ until the oven temperature was $200^{\circ} \mathrm{C}$. The spheres were removed from the vial and reduced to a final radius of $0.15 \mathrm{~cm}$ using $\mathrm{SiC}$ sandpaper. The purpose of reducing the radius from $0.2 \mathrm{~cm}$ to 0.15 $\mathrm{cm}$ was to remove any Cs which may have condensed onto the spheres during the cooling period in the oven.

The initial mass of $\mathrm{Cs}$ in each sphere was measured using instrumental neutron activation analysis (INAA). Comparator standards were prepared from a certified solution of $\mathrm{CsNO}_{3}$ purchased from High Purity standards. A $50 \mu \mathrm{L}$ aliquot of the standard solution was pipetted onto filter placed paper in a high density polyethylene vial with a volume of $200 \mu \mathrm{L}$. The standards were dried and capped with friction fit caps. The graphite spheres and comparator Cs standards were irradiated in the row 2 pneumatic tube irradiation position for 30 seconds in a neutron flux of $5.0 \times 10^{13} \mathrm{n} / \mathrm{cm}^{2} / \mathrm{s}$. The $127.5 \mathrm{keV}$ gamma ray from decay of ${ }^{134 \mathrm{~m}} \mathrm{Cs}$ produced by the reaction ${ }^{133} \mathrm{Cs}(\mathrm{n}, \mathrm{g})^{134 \mathrm{~m}} \mathrm{Cs}$ was measured by counting the sample $2.5 \mathrm{~cm}$ from the face of a HPGe detector. The samples were counted until at least 10,000 counts were measured in the $127.5 \mathrm{keV}$ photopeak. The initial mass of Cs in the 10 graphite spheres ranged from $12.2 \mu \mathrm{g}$ to $16.1 \mu \mathrm{g}$.

\section{Experimental}

The release experiment is carried out inside of a SiC tube mounted in a Lindberg tube furnace. A diagram of the experimental apparatus is shown in Figure 1. 


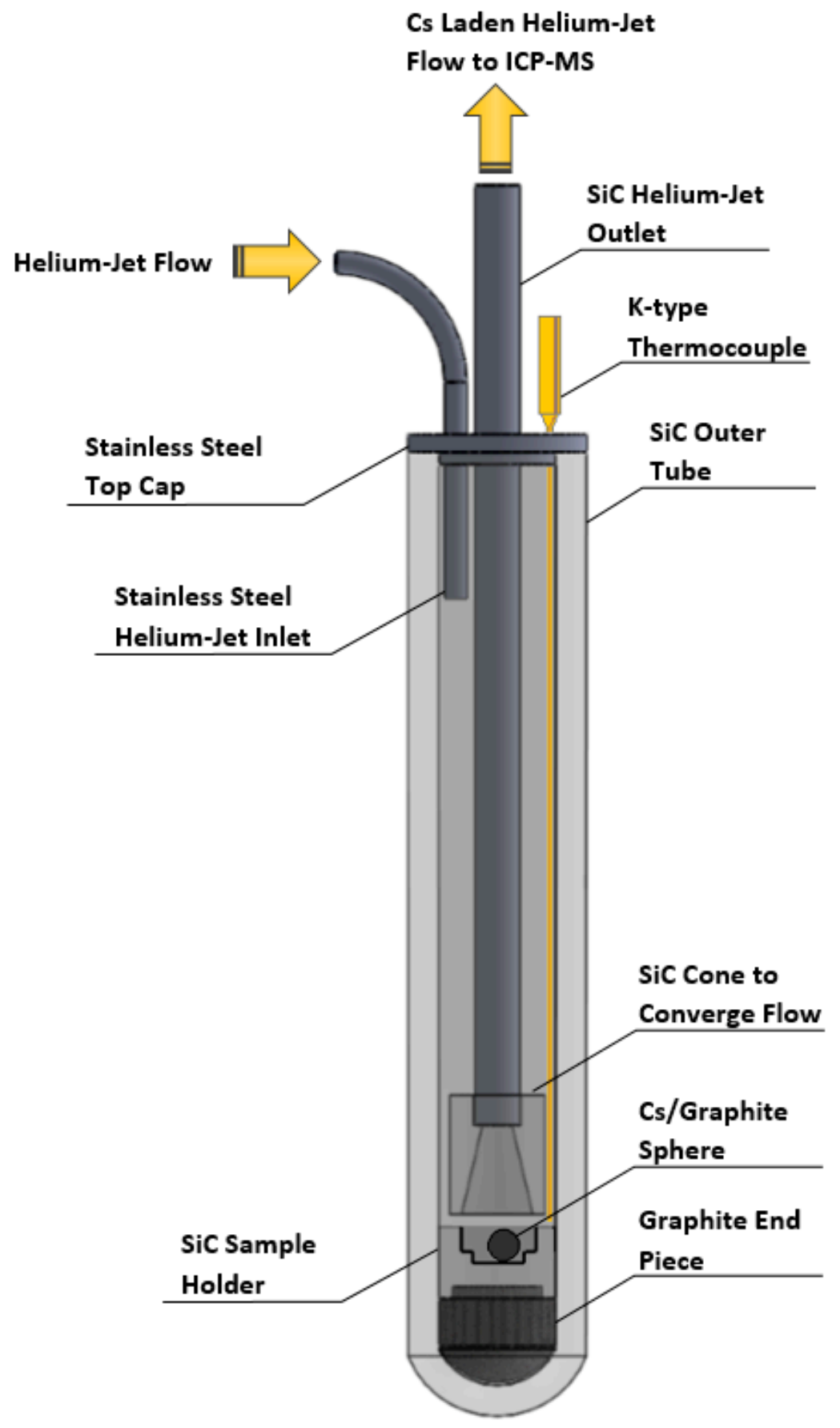

Figure 1. The release experiment takes place inside SiC tube that is closed at one end and mounted vertically in a Lindberg tube furnace. The arrows show the helium jet path. 


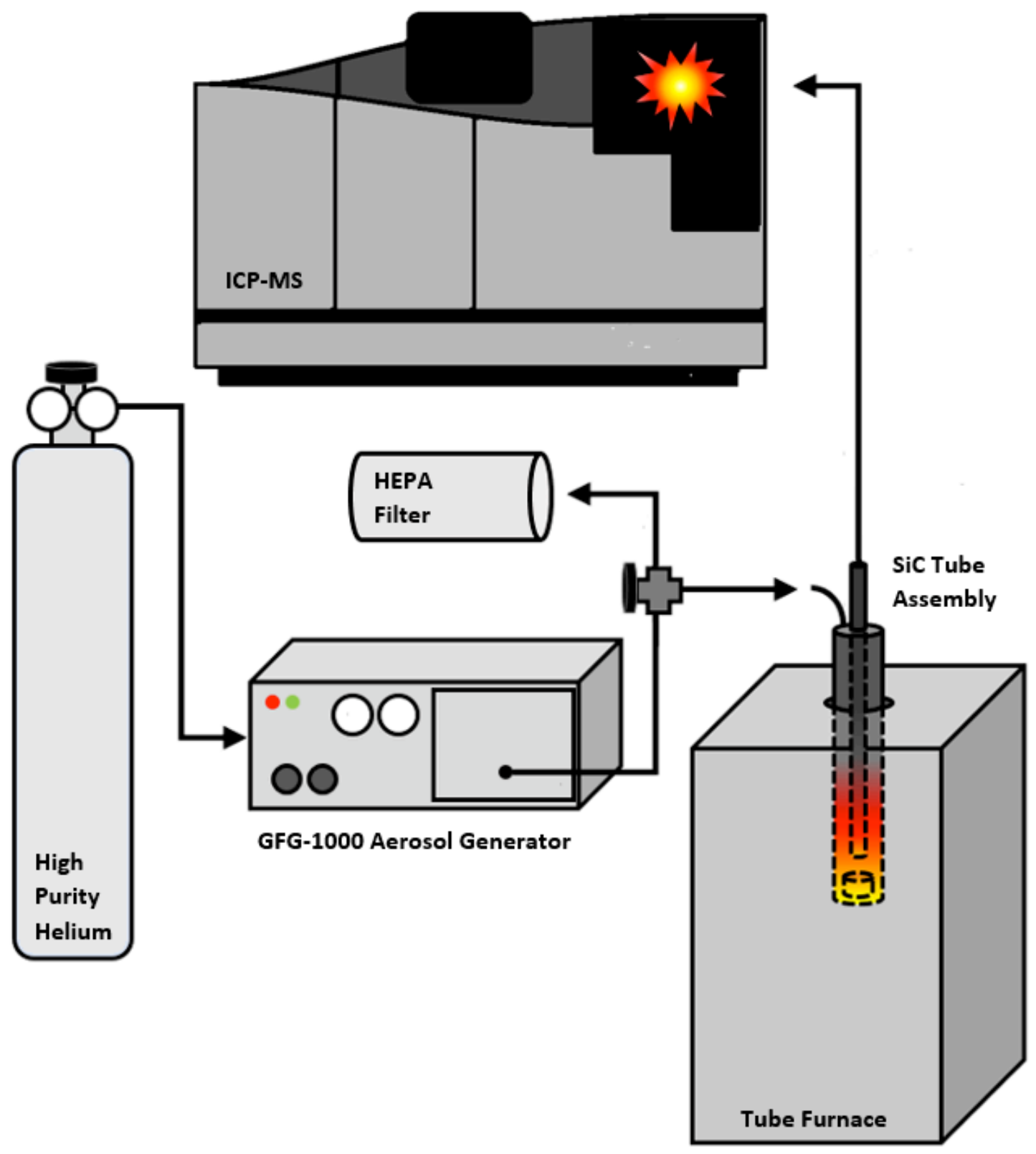

Figure 2. Schematic of the release experiment setup. The graphite sphere is located inside the SiC tube. Cs that is released is transported to the ICP-MS by a He-jet system.

The tube furnace heats the sample region of the SiC tube assembly to the target temperature. The top $10 \mathrm{~cm}$ of the $\mathrm{SiC}$ tube extends out of the tube furnace and is accessible. The temperature at the SiC holder is monitored using a K-type thermocouple. At the start of an experiment a room temperature graphite sphere containing a known mass of Cs is dropped into the heated sample holder. A sample holder constructed of $\mathrm{SiC}$ sits at the bottom of the assembly and holds the graphite sphere. The Cs 
released from the graphite sphere is transported from the diffusion chamber to an online ICP-MS for real time analysis using a carbon aerosol helium gas jet system.

A gas jet uses particles entrained in flowing gas to transport elements over long distances at room temperature [13]. The helium jet built for this experiment was modeled after the system used at the TRIGA reactor in Mainz, Germany which uses carbon nanocrystals [14]. A modified Palas GFG 1000 carbon aerosol generator was used to produce carbon particles with diameter lognormally distributed around $50 \mathrm{~nm}$. The aerosol generator functions by creating a spark discharge between two graphite electrodes which vaporizes carbon at the electrode surfaces. The vaporized carbon condenses into carbon particles entrained in helium that flows between the graphite electrodes at $4 \mathrm{~L} / \mathrm{min}$. The carbon aerosol laden helium is introduced into the SiC tube assembly using the He-jet inlet tube shown in Figure 2. The path of the helium jet inside the SiC tube assembly is illustrated in Figure 1 by the orange arrows. The helium jet flows around the graphite sphere where released Cs sorbs onto the carbon particles. The Cs laden helium jet exits the $\mathrm{SiC}$ tube and travels through a $3 \mathrm{~m}$ stainless steel tube that connects to a Perkin Elmer Nexion 300X ICP-MS via a two port quartz spray chamber, shown in Figure 3. The other port of the spray chamber contains a liquid nebulizer which continuously introduces a standard solution of $1.00 \mathrm{ng} / \mathrm{g}$ indium. The indium is used as an internal standard to monitor and correct for instrument drift over the course of the experiment. The helium jet operates for up to 6 hours during the experiment.

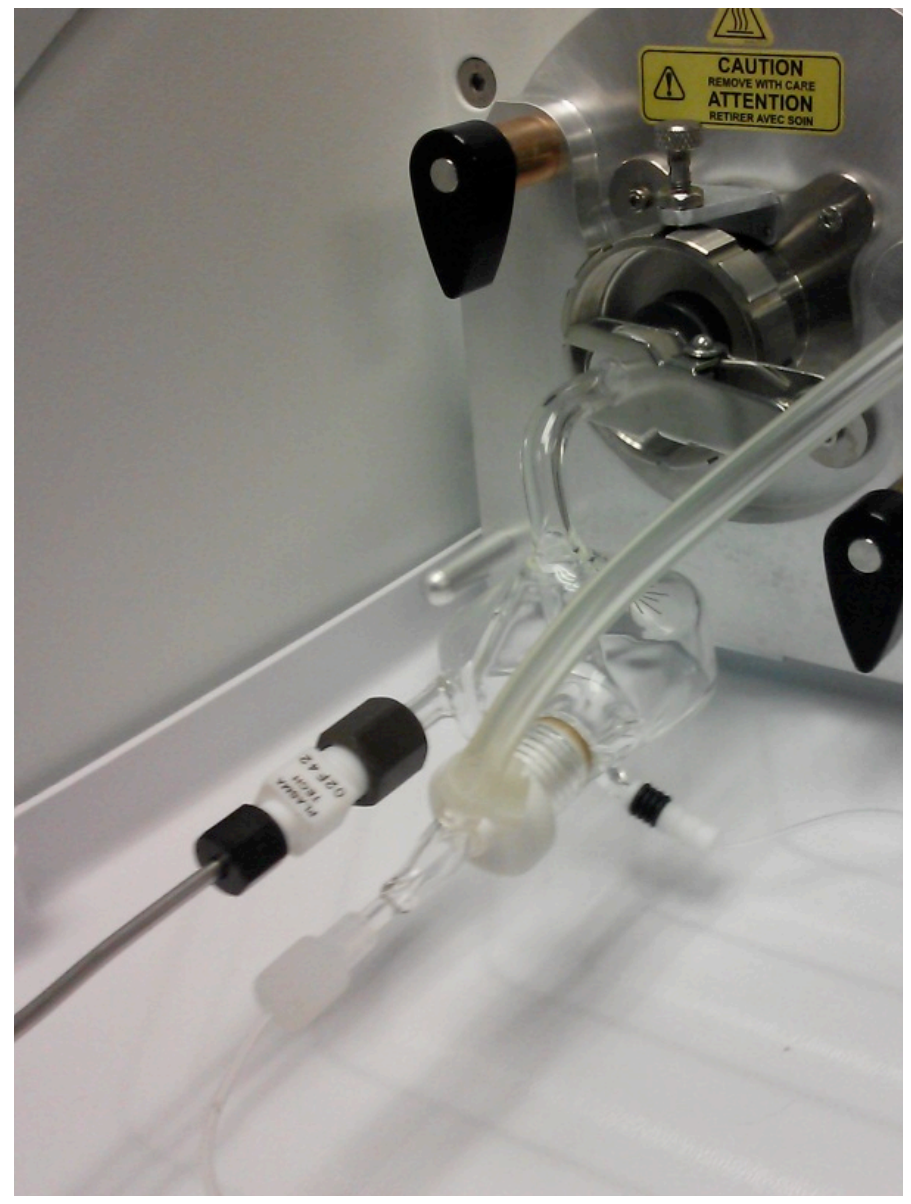


Figure 3: Dual inlet spray chamber. Inlet 1 (left) from He-jet with He flow rate of $1 \mathrm{~L} / \mathrm{min}$. Inlet 2 (right) from nebulizer that injects $200 \mu \mathrm{L} / \mathrm{min}$ of $1.00 \mathrm{ng} / \mathrm{g} \mathrm{In}$ as an internal standard.

At the start of an experiment, the $\mathrm{SiC}$ tube assembly is heated to the target temperature. The helium-jet system is turned on and the ICP-MS is started, tuned, and set to collect data for 30-60 minutes prior to introduction of the graphite sphere. Prior to sample introduction residual Cs on the SiC tube assembly surfaces is released and transported by the helium-jet to the ICP-MS detector. This constitutes a detector background of Cs. The background is monitored until it represents less than $1 \%$ of the expected Cs count rate. The He-jet outlet tube is disconnected while the SiC tube assembly is at the target temperature and the graphite sphere is dropped inside and, by gravity, descends into the SiC tube sample holder. The sphere is positioned as shown in the cutout section of Figure 1.

\section{Data and Analysis}

Diffusion coefficients are computed by measuring cumulative mass release or release rate from the graphite sphere as a function of time using ICP-MS. The value of the diffusion coefficient follows via a regression analysis.

The ICP-MS output is the count rate of Cs and the internal standard indium measured at the detector. It must be calibrated to produce a signal in units of an actual mass transport rate or quantity. The Cs count rate is scaled to the Cs mass transport rate by multiplication with the calibration factor, $F_{\text {calibration }}$ (g/count) which is a ratio of the total mass of Cs which has diffused $m_{\text {diffused }}(\mathrm{g})$ in an experiment and the total number of detector counts acquired by the ICP-MS $K_{\text {measured }}$ (counts) in the same time interval:

$F_{\text {calibration }}=\frac{m_{\text {diff }} \text { used }}{K_{\text {measured }}}$

The $m_{\text {diffused }}$ was calculated as the Cs mass difference of the graphite sphere before and after the diffusion experiment measured by INAA. The calibration factor is used to calculate the release rate $Z_{R}$ $(\mathrm{g} / \mathrm{s})$, using the detector count rate $k_{\text {measured }}$ (counts $\left./ \mathrm{s}\right)$ the calibration factor $F_{\text {calibration }}(\mathrm{g} / \mathrm{count})$. The experimental release rate is:

$Z_{R}=k_{\text {measured }} \cdot F_{\text {calibration }}$

Integration of the experimental release rate with respect to time yields the Cs mass diffused, and the experimental fractional release $F(t)_{\text {exp }}$ is the ratio of the mass diffused to the mass initially present in the sphere. For a given experiment, a plot of the $F(t)_{\text {exp }}$ vs. $t$ is fitted with solutions of eqn. 6 via a regression analysis to determine the diffusion coefficient.

Diffusion coefficients for Cs in IG-110 graphite at 1100, 1200, and 1300K are summarized in Table 1. Release rate and fractional release ICP-MS data for the analysis of Trial 10 are presented in Figure 4 .

Table 2. The table lists the diffusion coefficients calculated by fitting solutions of eqn. 6 to the experimental data using a regression algorithm. The initial and final Cs content was measured using INAA. 


\begin{tabular}{|c|c|c|c|c|c|c|}
\hline Trial \# & $\begin{array}{l}\text { Initial Cs } \\
\text { Content } \\
(\mu \mathrm{g})\end{array}$ & $\begin{array}{l}\text { Final Cs } \\
\text { Content } \\
(\mu \mathrm{g})\end{array}$ & Temperature (K) & $\begin{array}{l}D\left(m^{2} / s\right) \\
\text { [Eqn. } 6 \\
\text { Regression] }\end{array}$ & $\begin{array}{l}\mathrm{D}\left(\mathrm{m}^{2} / \mathrm{s}\right) \\
\text { [Eqn. } 7 \\
\text { Regression] }\end{array}$ & $\begin{array}{l}\mathrm{D}\left(\mathrm{m}^{2} / \mathrm{s}\right) \\
\text { [INAA Mass } \\
\text { Difference] }\end{array}$ \\
\hline 1 & 14.5 & 11.7 & 1100 & $9.5 \times 10^{-13}$ & $8.5 \times 10^{-13}$ & $1.3 \times 10^{-12}$ \\
\hline 6 & 12.2 & 10.3 & 1100 & $6.3 \times 10^{-13}$ & $5.9 \times 10^{-13}$ & $8.5 \times 10^{-13}$ \\
\hline 7 & 16.1 & 13.8 & 1100 & $1.4 \times 10^{-13}$ & $7.1 \times 10^{-14}$ & $1.8 \times 10^{-13}$ \\
\hline 8 & 13.9 & 11.3 & 1100 & $1.0 \times 10^{-12}$ & $8.0 \times 10^{-13}$ & $1.1 \times 10^{-12}$ \\
\hline 2 & 12.7 & 11.1 & 1200 & $8.0 \times 10^{-13}$ & $8.5 \times 10^{-13}$ & $7.8 \times 10^{-13}$ \\
\hline 4 & 14.3 & 11.8 & 1200 & $1.2 \times 10^{-12}$ & $1.5 \times 10^{-12}$ & $1.1 \times 10^{-12}$ \\
\hline 10 & 15.3 & 12.4 & 1200 & $1.3 \times 10^{-12}$ & $1.5 \times 10^{-12}$ & $1.4 \times 10^{-12}$ \\
\hline 3 & 12.9 & 8.56 & 1300 & $4.9 \times 10^{-12}$ & $1.1 \times 10^{-11}$ & $4.2 \times 10^{-12}$ \\
\hline 5 & 12.6 & 8.83 & 1300 & $4.3 \times 10^{-12}$ & $8.3 \times 10^{-12}$ & $3.6 \times 10^{-12}$ \\
\hline 9 & 14.7 & 10.6 & 1300 & $2.5 \times 10^{-12}$ & $3.7 \times 10^{-12}$ & $2.7 \times 10^{-12}$ \\
\hline
\end{tabular}

The sphere introduction time is defined as $t=0$. Because the time required for transport to the ICP-MS and the time required for the sphere to come to thermal equilibrium with the cell are both non-zero and not precisely known, there is a slight delay in data acquisition. Additionally, small deviations from ideal transport behavior of the FP laden aerosol stream (e.g. diffusional broadening, interactions with component surfaces) result in broadening of the signal, which would ideally be represented as proportional to a delta function. These effects are obvious from the release rate plot in Figure 4, below, as initially the release rate is zero and is increasing, which does not reflect physical diffusion behavior based on the assumptions of the release model. Conversely, when fractional release data is considered, the initial data points correspond more closely to physical behavior (zero cumulative release at $t=0$, and increasing thereafter). The accuracy of diffusion coefficients computed from the rate data may be improved by excluding some initial data points or by redefining the initial time. This would require additional assumptions and/or measurements, as the regression analysis would be affected significantly. These manipulations would have a much smaller effect on the fractional release data series (i.e. the fractional release regression is less sensitive to redefining the initial time or excluding the corresponding data points), and therefore it is believed that the fractional release regression gives the best estimate of the diffusion coefficient. For comparison, we have also calculated diffusion coefficients via regression analysis using the rate equation (eqn. 7), with similar results.

Data obtained during the time interval from sphere introduction $(t=0)$ to the moment the furnace is turned off ( $\left.t=t_{\text {end }}\right)$ has been considered during fitting procedures. It is important to note that a small amount of additional diffusion occurs after $t_{\text {end }}$, as the furnace cools down from the experimental temperature. This additional transport is monitored by the ICP-MS, and incorporated into the calibration factor. However, it is excluded in all regression analyses as we wish to consider diffusion at constant temperature.

We also note that the INAA mass difference measurement and the width of the annealing time interval $\left(t_{\text {end }}\right)$ gives an indication of the diffusion coefficient in itself, which is an exact solution from eqn. 6 . However, there is no way to exclude diffusion which occurs after furnace shutdown when computing diffusion coefficients in this way, and as the ICP-MS data gives the cumulative release (or rate) at many time points, the system is overdetermined and a regression analysis should give the best estimate of the 
effective diffusion coefficient. We present the values corresponding simply to the INAA mass difference measurement for comparison in Table 2.
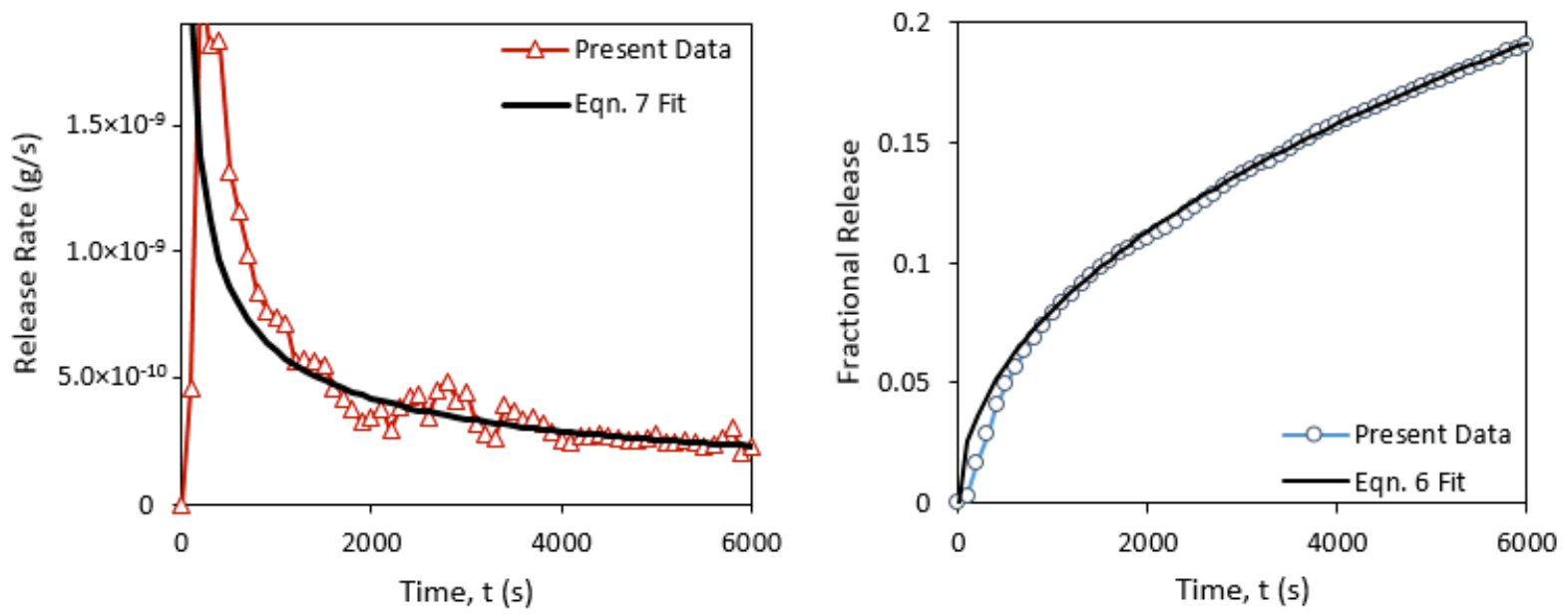

Figure 4. Sphere 10 release flux plot (left) and fractional release plot (right) with best fit theoretical curve corresponding to $D=1.3 \times 10^{-12} \mathrm{~m}^{2} / \mathrm{s}$.

The Arrhenius equation is used to describe the temperature dependence of the diffusion coefficient in terms of the pre-exponential factor $D_{0}\left(\mathrm{~m}^{2} / \mathrm{s}\right)$ and corresponding activation energy $E(\mathrm{~J} / \mathrm{mol})$. We have obtained $D_{0}$ and $E$ in the temperature range of $1100-1300 \mathrm{~K}$ from an Arrhenius plot of the data in columns 4 and 5 of Table 2. These values and uncertainties are given in Table 3.

Table 3. Pre-exponential and activation parameters for diffusion of Cs in IG-110 graphite between $1100 \mathrm{~K}$ and $1300 \mathrm{~K}$.

\begin{tabular}{llllll}
\hline Material & FP & $D_{0}\left(\mathrm{~m}^{2} / \mathrm{s}\right)$ & $\pm \Delta \ln D_{0}$ & $E(\mathrm{~J} / \mathrm{mol})$ & $\pm \Delta E(\mathrm{~J} / \mathrm{mol})$ \\
\hline $\mathrm{IG}-110$ & $\mathrm{CS}$ & $1.0 \times 10^{-7}$ & 2.90 & $1.1 \times 10^{5}$ & $2.8 \times 10^{4}$ \\
\hline
\end{tabular}

Our data as well as selected literature results reported for diffusion of Cs in IG-110 and similar materials are presented for comparison in Figure 5: 


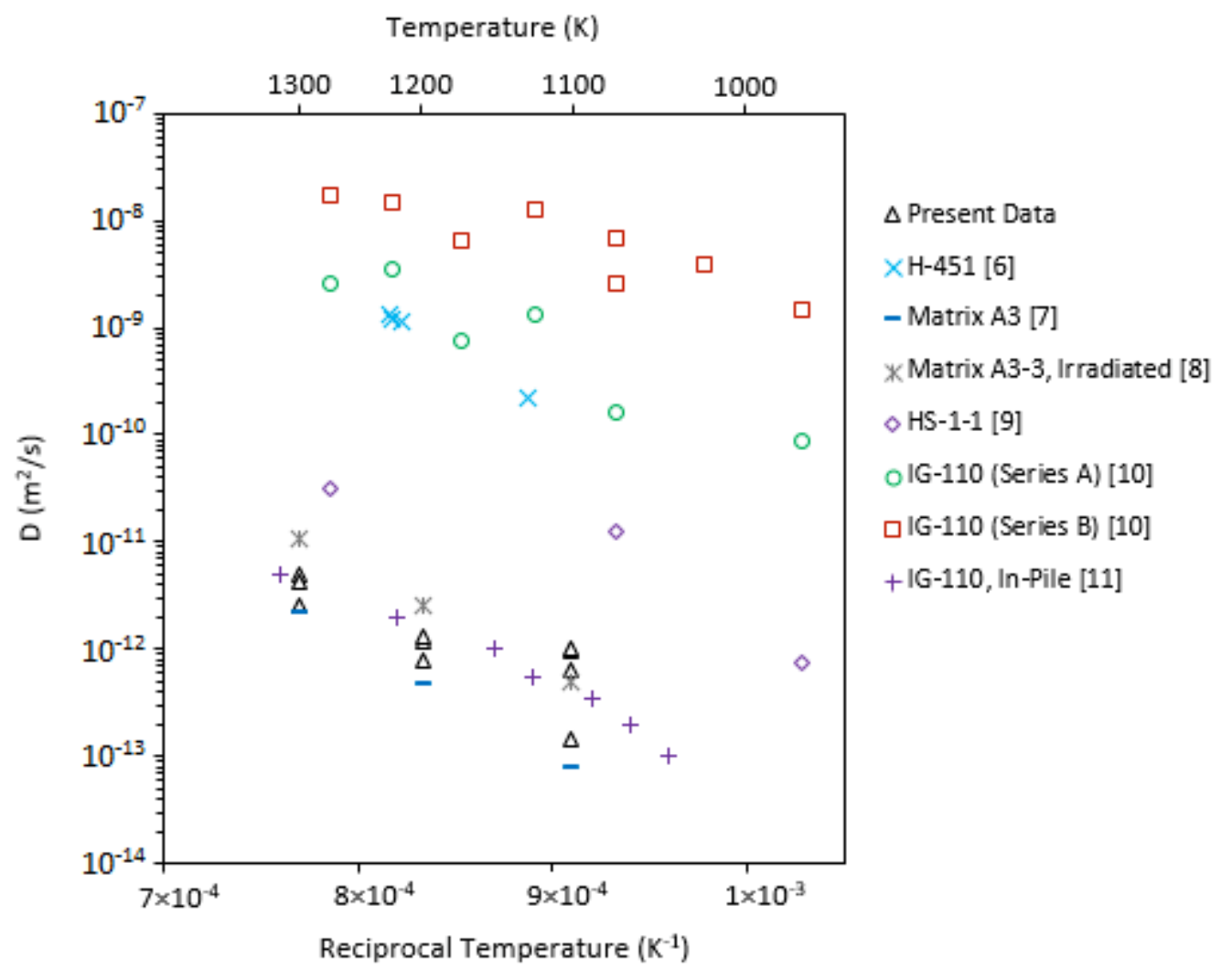

Figure 5. The measured diffusion coefficients from this experiment plotted versus reciprocal temperature with other values for various graphites reported in the literature.

\section{Discussion}

We have used a simple model for the release of Cs from graphite, but the results suggest the classical diffusion model is adequate for the range of conditions tested and the experimental time interval. However, this may not be the case when graphite contains other FPs, adsorbents, or is subjected to irradiation or oxidative stresses. In modeling, we have assumed that the graphite spheres are perfectly spherical, FP is initially uniformly distributed in them, the spheres are in infinite space (not touching any surface), and that the surface concentration of FP is zero. Sensitivity of results to deviations from these assumptions is likely small (our preliminary investigations of small deviations from non-uniform concentration confirm this), but should be investigated in the future.

It is evident from Figure 5 that there are differences in results, which is typical of measurements of this type. Some variation is due to differences in the properties of the materials tested, while the nature of the measurement technique likely plays a role as well.

Myers [5] and Hayashi [10] have reported that effect of fast neutron damage causes a decrease in the diffusivity by orders of magnitude. In contrast, Hoinkis [8] reported no change in measured diffusion 
coefficients when comparing irradiated and as-received graphite. Interestingly, diffusion coefficients obtained by Hayashi [11] from in-pile irradiated IG-110 graphite correlate well with those obtained in the present work. This suggests that Cs diffusion coefficients in IG-110 may not be strongly dependent on fast neutron fluence. Hayashi observed wide variation in the results when testing unirradiated IG-110 graphite in separate experiments [10] and suggested material inhomogeneity among different production lots was responsible for the variation. It may therefore be important to test representative samples from each lot of IG-110 to determine if the measured diffusion coefficient is within a tolerable range.

\section{Conclusions}

We have measured diffusion coefficients of Cs in IG-110 in the temperature range of 1100-1300K by using the release method and ICP-MS. We have used a carbon aerosol laden helium-jet system to transport Cs diffusing from a heated graphite sphere to an online ICP-MS to determine release rates and cumulative release in real time. We have obtained:

$D_{C s}=\left(1.0 \times 10^{-7} \mathrm{~m}^{2} / \mathrm{s}\right) \exp \left(\frac{-1.1 \times 10^{5} \mathrm{~J} / \mathrm{mol}}{R T}\right)$

The method we have developed is easily adaptable to measure diffusion of other fission products or of multiple fission products, diffusion in other types of graphite or other materials of interest, and the effects of oxidation and other chemical or physical stresses on diffusion behavior. We have observed that Cs diffusion in IG-110 graphite in the temperature range of 1100-1300K may be adequately described by the classical diffusion equations.

Acknowledgements: This research was supported by a NEUP-2982 grant, "A Research Program for Fission Product/Dust Transport in HTGRs" by the U. S. Department of Energy. The spheres were machined at the MURR Science Instrument shop, and the measurements, including NAA, were conducted at MURR facilities. We acknowledge support of several colleagues including Drs. Rajesh Gutti and Matt Simones regarding use of the Palas particle generator, and Professor Tushar Ghosh for information on the existing literature.

\section{References}

[1] "Mechanistic source terms white paper". INL/EXT-10-17997. Idaho National Laboratory, Idaho, US. (2010).

[2] IAEA Tech Doc 978. Fuel performance and fission product behavior in gas cooled reactors. IAEA (1997). p 461.

[3] Becker Technologies GmbH. Fission product retention in HTGR confinement buildings. Summary of final report BF-R-40.039-1.0 (2010. original in German, 1988). 
[4] E. Hoinkis, Editor. Transport of fission products in matrix and graphite. HMI-B372. Proceedings of a colloquium held at Hahn-Meitner-Institut, Berlin, 1981 (published, June 1983). These proceedings contain many papers of interest, we cite relating to the release method below.

[5] B. F. Meyers. A Review of the diffusion of selected fission product metals in polycrystalline graphite. ibid, p. 56.

[6] B. F. Meyers and D. W. Hill. Cesium diffusion in H-451 graphite. ibid p. 68.

[7] H. J. Leyers. Cesium release out of graphite matrix A3 in flowing helium. ibid p. 103.

[8] E. Hoinkis. The determination of diffusion coefficients of cesium and silver by the release method in as received, oxidized and neutron irradiated graphite-matrix. ibid p. 77.

[9] R. B. Evans, W. Davis, A.L. Sutton. "Cesium diffusion in graphite". ORNL-5648, Oak Ridge National Laboratory, Tennessee, US. (1980)

[10] K. Hayashi and K. Fukuda. Diffusion coefficients of cesium in un-irradiated graphite and comparison with those obtained from in-pile experiments. J. Nuc. Materials 168 (1989) 328-336.

[11] K. Hayashi, T. Kikuchi, F. Kobayashi, K. Minato, K. Fukuda, K. Ikawa, K. Iwamoto. Distribution of fission products in irradiated graphite materials of HTGR fuel assemblies: Third and fourth OGL-1 fuels. J. Nuc. Materials 136 (1985) 207-217.

[12] D. R. Olander, Fundamental Aspects of Nuclear fuel Elements. Energy Research and Development Administration. 1976.

[13] Rengan K., and Meyer R.A. Ultrafast Chemical Separations. National Academy Press, Washington D.C. 49-58 (1993).

[14] Eibach M., Beyer, T., Blaum K., Block M., Eberhardt K., Herfurth F., Geppar C., Ketalaer J., Ketter J., Kramer J., Krieger A., Knuth K., Nagy S., Narthershauser W., and Smorra C. "Transport of fission products with a helium gas-jet at TRIGA-SPEC". Nucl. Instrum. Methods Phys. Res., Sect. A, 613:226-231 (2010). 